\title{
Chapter 4 \\ The Use of Backcasting to Promote Urban Transformation to Sustainability: The Case of Toyama City, Japan
}

\author{
Kazumasu Aoki, Yusuke Kishita, Hidenori Nakamura, and Takuma Masuda
}

\begin{abstract}
Envisioning urban sustainability demands to embrace divergent values of various stakeholders. Implementation of policies realizing city's future visions needs support from a wide range of general public. Hence, merits of participatory approach to backcasting scenario-making have been noted. Although experimenting such approach should be more encouraged, it remains to be seen whether lay citizens can generate their scenarios with required level of rationale and soundness. This chapter addresses this important, but yet unexplored concern by taking two potentially contrasting perspectives. One is "divergence" found in processes where citizens express their pluralistic interests and preferences in an unconstrained manner. The other is "convergence" found in where such a diversified plurality is circumscribed and composed to engender in outcomes some form of converged context. A trade-off relationship may arise between these two and the chapter seeks if any balance can be upheld. To explore such question, a participatory workshop was held in Toyama city, Japan where a handful numbers of citizens envisioned in two separate groups their desirable future via backcasting city's sustainable features. In analyses, outcomes of both groups' scenarios were compared and also index of consistency-based text structures endogenous to the scenarios was quantitatively gauged by computational simulation technique. Findings suggest that while a broad spectrum of socioeco-
\end{abstract}

This work was performed when the fourth author used to be a bachelor student at the University of Tokyo.

K. Aoki $(\bowtie)$

University of Toyama, Toyama, Japan

e-mail:kzaoki@eco.u-toyama.ac.jp

Y. Kishita

The University of Tokyo, Tokyo, Japan

H. Nakamura

Toyama Prefectural University, Toyama, Japan

T. Masuda

MS\&AD Systems Company, Tokyo, Japan

(C) The Author(s) 2020

O. Saito et al. (eds.), Managing Socio-ecological Production Landscapes and

Seascapes for Sustainable Communities in Asia, Science for Sustainable

Societies, https://doi.org/10.1007/978-981-15-1133-2_4 
nomic and ecological elements was incorporated, they were yet founded upon a fairly good degree of logically coherent means-end based structures. The chapter then considers the meaning of such a balance for backcasting scenario-making with implications for further research agenda and future policy-making.

Keywords Urban transition · Future visions - Backcasting scenario - Participatory approach $\cdot$ Citizen dialogue $\cdot$ Sustainable society scenario (3S) simulator

\subsection{Introduction}

\subsubsection{Background Issues of This Study}

In recent years, it has become increasingly evident that various aspects of contemporary cities place too high a burden on the environment. Population, industry, commerce, energy, food consumption, and culture are some of the factors leading to rapid concentrations in urban areas in both developed and developing countries (Wolfram and Frantzeskaki 2016). Therefore, like Bulkeley and Betsill (2003) and others (Hodson and Marvin 2010; Loorbach et al. 2016; Hodson et al. 2017; Frantzeskaki et al. 2018) have stated, urban sustainability transitions have emerged as an urgent policy agenda concerning possibilities for making fundamental transformative changes on this current trend to keep cities from following unsustainable pathways.

In this regard, since the end of the 1990s, relevant disciplines (e.g., sustainability science, socio-engineering, sustainability transitions, and so forth) have argued the merits of envisioning cities' sustainable futures and contemplating possible pathways toward realizing such futures (Gallopin et al. 1997; Matsuoka et al. 2001; Glenn and The Future Groups International 2005). Such interests in scenariomaking also extend to a wide range of issues including climate change, biodiversity, sustainable development goals (SDGs), and landscape approaches such as Satoyama and Satoumi, which promote socio-ecological production landscape and seascapes (Tress and Tress 2003; Carpenter et al. 2005; International Panel on Climate Change (IPCC) 2007; Ten Brink et al. 2010; Kanie 2017).

Among those scenario-makings, many now regard a design method (and also a way of thinking) called "backcasting" (BC), to be particularly promising (Robinson 1990; Dreborg 1996; Mander et al. 2008; Nishioka 2008; Kok et al. 2011; Kishita et al. 2016). BC scenario-making is defined and understood as a series of processes where stakeholders: (1) first craft visions of their ideal and desirable cities whose functioning standards and conditions are to be achieved in a relatively distant future (e.g., the year 2050 or beyond) and (2) think through pathways chronologically backward from the future to the current period in terms of what must be done to realize such visions. 
Having received closer attention from both the academic and nonacademic, practical fields, however, the BC methods have the following shortcomings that have not yet been explored (Vergragt and Quist 2011; Kishita et al. 2017). (1) While BC scenario-making has mostly been carried out by relevant experts and professionals, involving lay persons in its process has not yet been researched to a great extent (Kishita et al. 2016; McLellan et al. 2017). Considering the fact that any processes relating to transitioning toward sustainable cities are direct and indirect consequences of collective decisions made by a wide array of stakeholders, nonexperts and nonprofessionals should also take initiatives in BC scenarios (Rotmans et al. 2000; Kasemir et al. 2003; Albert 2008; Umeda 2008; McLellan et al. 2017; Frantzeskaki et al. 2018). (2) The resulted BC scenarios are not yet formally or effectively implemented in practice and not having as much impact as already existing policies and measures. That is partly because it has been difficult to embed such participatory BC scenario-making into ongoing, conventional policy processes (Soria-Lara and Banister 2017; Kishita et al. 2016).

\subsubsection{Analytical Perspectives and Research Questions}

In order to overcome such shortcomings, researchers must take into consideration the fact that envisioning sustainability of future cities inevitably demands to embrace divergent interests, preferences, and knowledges of various stakeholders (Umeda 2008). That is not only because, as most often said in the field of sustainable science, the concept of sustainability itself reflects a bundle of multiple value systems (Kishita et al. 2010), but also because any cities have their own societal functioning that is of multifaceted configurations working in an interrelated, complementary manner (Hodson et al. 2017). In this regard, letting the general public participate in BC scenario-making certainly makes it more plausible to consider more diverged pluralistic opinions and relevant local knowledge to emerge and be expressed throughout the process (McLellan et al. 2017). After all, the citizens have an ultimate stake and say in the direction of their own future cities, and without ensuring their credible commitments and continuous cooperation in the longer term, there will be no effective endeavor toward urban sustainability transition. Also, the recent arguments on SDGs and biodiversity tend to view participatory approach as essential to empower grassroots citizens whose knowledge and experiences are key enabling elements for successful future visioning (Kanie 2017).

At the same time, however, citizen participatory processes inevitably increase the difficulties to mediate interests of individuals, especially when these interests are not bucked by rational reasoning or public-minded causes. In democratic nations, it has indeed been noted that citizens rather easily follow the majority, occasionally being swallowed up by a tide of enthusiasm. Note also that this type of skepticism, sometimes called "populism," has constantly been associated with more direct, mass participatory democracy. Though anecdotal, a Japanese local administrative official we once spoke with said: "Most of the time, citizens just demand what they want only for themselves." 
We then must ask how such risk can be reduced and governed to be able to generate more participatory BC scenario-making with a satisfactory level of rational and soundness (van der Heijden 2005) and to mobilize such scenarios as a practical policy tool for developing cities' sustainable futures, which indicates a need for deep transformative change from the current orientation (Kishita et al. 2018). Therefore, in this chapter, we consider two potentially contrasting perspectives. One is "divergence" found as diverged processes and opinions where such lay individuals as general citizens act as dispersed dots, expressing their pluralistic interests, preferences, and knowledge in processes in an unconstrained manner. The other is "convergence" found as converged outcomes and structures where such a diversified plurality is circumscribed and composed as connected dots, engendering in the scenarios some form of converged context or bases normally found in practical policy documents and texts. Between these two extremes, one may find a trade-off relationship and this is the area on which we will focus to explore if any balance can be upheld.

In answering this question, one should note that resolving the trade-off is expected to be more difficult to achieve using the BC method, especially compared to the more conventional method called "forecasting" (FC). FC has long been the dominant practical method and is of incremental nature and thus more inclined to path-dependency. Under FC methods, policies and measures tend to be planned and made incrementally, allowing them to be based on and drawn from the current version. Thus, reliance on FC can more likely assure the generation of solutions which are compatible to and stable with the ongoing functioning and configurations of the societal system. Nevertheless, literature in sustainability science and sustainability transitions has noted that path-dependency must be overcome for a society to solve so-called "wicked problems" and be transformed into a more sustainable one. Problems are considered wicked in the sense that they only worsen if we take the ongoing functioning and configurations of the current societal system for granted and let solutions be based on and drawn from them (Robinson 1990; Zellner and Campbell 2015; Loorbach et al. 2016).

In contrast, BC is basically understood as methods that can more likely allow greater proactive and pathbreaking changes to be sought and accommodated through scenario-making. This means that the BC methods are more inclined to include divergent ways of thinking, and involve processes where more creative, innovative ideas and thoughts can emerge pluralistically and be expressed (Robinson 1990; Dreborg 1996). In line with this understanding, one study even argues that under the $\mathrm{BC}$ method, if it is for the sake of generating scenarios with more edgy, pathbreaking solutions, some degree of gap or incoherence that may be found in causal relationships between means and ends is not necessarily considered to be overly problematic (Kishita et al. 2016). Thus, we explored whether and to what extent such BC scenarios-making could be converged in a reasonably rationalized fashion via engendering some form of sound, coherent bases and structures being attached to the texts of the resulted scenarios (Albert 2008; Alcamo et al. 2008).

Below, the chapter articulates in the second section as to how we designed and implemented a series of workshops (WS) where lay citizens participated and lays 
out the methods and techniques used to ensure the participants' unconstrained, spontaneous dialogues while backcasting desirable future city. The third section then explains two verification approaches undertaken to explore the research questions drawn from the above-mentioned perspectives. The one corresponds to "divergence" concern to see if the participants' values were pluralistically expressed. The other corresponds to "convergence" concern to see if and to what extent coherence can be found. The fourth section provides analytical outputs and relevant discussions. In the final fifth section, we argue as to what the resulted findings mean to the use of backcasting scenario-making in policy practice and also point to the direction of further research and its significance.

\subsection{Designs of Backcasting Scenario-Making: Citizen Participatory Workshop}

\subsubsection{Setting of the Workshop Held in the City of Toyama, Japan}

\subsubsection{Reasons for Choosing the Targeted City}

We chose the city of Toyama in Japan to be the study area for BC scenario-making. Toyama city has 420,000 inhabitants. Its location is near the center of Honshu, the main island of Japan and is in the Hokuriku region, about $450 \mathrm{~km}$ northwest of the Tokyo Metropolitan area.

Today, Japan as a nation faces a series of severe and rapidly growing socioeconomic problems (e.g., sharp population decline, highly aging society with a declining birthrate, severe fiscal deficit, and excess concentration of population and industry in the Tokyo Metropolitan area) that are considered to be endemic to economically advanced nations. Among the other cities of a similar size in Japan, Toyama city is regarded to be proactively committed to dealing with such problems.

Since the 2000s, the local government of Toyama city (TCG) has implemented so-called compact city policies under which outside residents are induced and incentivized mostly with monetary subsidies to move to and live their lives in the city's center. Concentration of the city's population and societal functions in one particular geographic area enables TCG to diminish its administrative expenses.

In this line of policy deployment, improvement of the local public transportation network (made of light rail transit, railroads, and buses) has been vigorously sought by TCG to reduce citizens' heavy dependence on the daily use of private automobiles. Living without car use (meaning the city life within walking distance) has also been a long-term objective pursued over decades by TCG, serving to address two of the socioeconomic problems. One is climate change; switching from private automobiles to public transportations can cut $\mathrm{CO}_{2}$ emissions. The other is social welfare; enhanced physical strength with better walking abilities and thus extended healthy 
life expectancy can cut medical expenses from rapidly skyrocketing for the elderly. In the eyes of TCG, all of these efforts enable building a city that is caring and friendly to both humans and the environment. As a result, Toyama city seeks to make itself the chosen destination among the other cities in Japan, with the hopes of attracting a larger population and increased investment (Toyama City 2017).

At the same time, however, TCG's compact city policies pose a thorny problem concerning how the city achieves greater levels of coordination and symbiosis between its central and periphery areas. In fact, we encountered a number of citizens who have raised their concerns and worries that there might be a potentially irreversible disparity occurring from prospective continuous decline in the administrative services and resources allocated to the peripheral, hilly, and mountainous area. Also, some of those tend to see that a series of socioeconomic revitalization measures-understood by TCG as one of the most pressing agenda and taken almost exclusively in the central area- has been determined by processes not being open enough to include a wider spectrum of individuals who can better represent grassroots and civil societal viewpoints. From these perspectives, it can be said that the city faces a governance issue where a way of making its collective decision should be attuned to a more direct citizen participatory initiative.

In addition, Toyama city has a unique urban setting where surroundings of the terrain make the world's rare landscape environment. Such a landscape endows the city with a $4000 \mathrm{~m}$ height difference which extends from the peak point of the Tateyama mountain range (3000 $\mathrm{m}$ height) in the south to the bottom of Toyama Bay (1000 m depth) in the north. TCG tries to take advantage of this particular geographical characteristic to appeal the city's attractiveness. That in turn means that, on the one hand, the city accelerates bolstering and upgrading of urban functions in its central area, but at the same time the city needs to conserve and enhance a wide array of natural capitals in its peripheral rural area. We thus argue that such a diverse socioeconomic and ecological landscape constitutes an interesting context in which how the participating citizens envision desirable features of their future city can be affected.

\subsubsection{Membership of WS Participants}

All the participants volunteered to participate with understanding of the purpose of the WS. The total number of such participants was 16 , of whom 9 were male. They extended from teenagers to elderly people in their 70s. Everyone but two participants are Toyama residents. The two nonresidents have ongoing business interests in the city and travel into the city every week day. Thus, all participants are direct stakeholders in the path of the city's future. In 2016, the WS was held as a threetime event on August 6th and 27th and on October 22nd, each involving 5 to 6-h sessions in the afternoon with intermissions.

During the WS, the participants were evenly divided into two groups (Groups A and B) based on gender and age (see Table 4.1). Each group was facilitated by two of our authors, who took a content neutral stance, not intervening in the participants' talks in terms of substance. Also, the facilitators had prepared in advance the 
Table 4.1 Membership of the Groups A and B

\begin{tabular}{l|l}
\hline Group A & 5 males $(70 \mathrm{~s}, 60 \mathrm{~s}, 30 \mathrm{~s}, 20 \mathrm{~s}, 10 \mathrm{~s})$ \\
\cline { 2 - 2 } & 3 females $(40 \mathrm{~s}, 40 \mathrm{~s}, 20 \mathrm{~s})$ \\
\hline \multirow{2}{*}{ Group B } & 4 males $(50 \mathrm{~s}, 30 \mathrm{~s}, 20 \mathrm{~s}, 20 \mathrm{~s})$ \\
\cline { 2 - 2 } & 4 females $(70 \mathrm{~s}, 50 \mathrm{~s}, 40 \mathrm{~s}, 20 \mathrm{~s})$ \\
\hline
\end{tabular}

documents describing the procedures and methodologies and applied them equally to the two groups' talks in order not to generate any managerial differences between groups. These were the measures being implemented for governing the WS because of our intent to achieve neutrality and comparability of the contents of both groups' scenarios. In this manner, we made it possible to analyze the different outcomes being generated from the same processes.

\subsubsection{Methods and Techniques of Dialogue Among the Workshop Participants}

\subsubsection{Rules and Norms for Free Dialogue}

All participants were asked not to reveal any of their attributes such as professions, positions, and titles throughout the entire period of the WS. We thought this rule was important because people tend to be intimidated or feel restrained while talking to someone who they feel holds a superior position or has more expertise. At the same time, the participants were guided "not to deny, dominate, and conclude" their dialogue in any way or at any time (Sakano 2011). At the WS, these rules and norms were applied to the two groups for the sake of creating and maintaining an arena in where each one of the participants can be spontaneous and independent with others and thus can think and express opinions and preferences freely.

In addition, by setting the scenarios targeting a relatively longer term (in this case the year 2064, 48 years from the time of convening the WS in 2016), we meant to craft visions as ones radically different from, and more creative than those of the status quo. Also, the year 2064 points to a more distant future if compared to targeted years of the TCG's policies on urban development and planning. Thus, we thought that the participants were incentivized to become liberated from and uninfluenced by the current policies being pursued by the TCG.

\subsubsection{Use of Key Items for Guidance}

At the WS, we introduced a list of "key items" in relation to the issues of the city's sustainability. Those key items were the ones actually used in the TCG's general administrative plan in effect from 2007 to 2016 (Toyama City 2007). The plan had used the list to provide examples of certain aspects concerning relevant policies and measures indicating how TCG makes its decisions on urban development and 
Fig. 4.1 Alignment of nodes and links of Logic tree

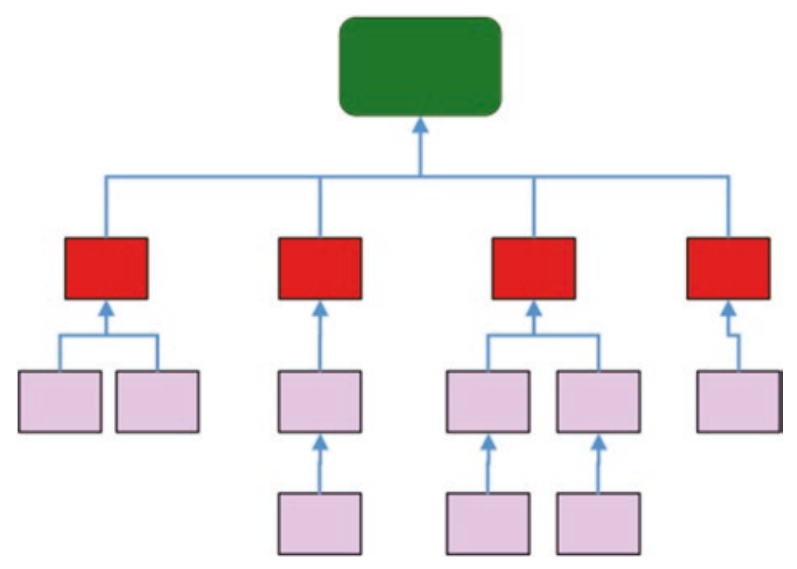

management. We also added to the list four broad elements: well-being, nature, economy, and society. These elements are equivalent to the ones proposed via a concept called a "sustainability compass" (AtKisson and Lee Hatcher 2001). Each broad element was divided into three subcategories respectively. For example, "well-being" consisted of "learning," "health," and "safety." Each subcategory then indicated a number of its own key items. For example, the key items listed for "learning" were "home education," "school education," and "life-long education."

During their dialogues, the participants were told to refer to the list while deliberating on the matter, but at the same time they were strongly advised not to be restrained by it as well. The reason for showing the list was founded on a procedural methodological perspective. It was meant to make sure that the multifaceted, pluralistic characteristics of urban sustainability issues were well contemplated by the participants and properly reflected the outcomes of the scenarios with the minimum necessary level and amount of dialogue.

\subsubsection{Use of Logic Tree}

As shown in Fig. 4.1, we employed an analytical instrument called a logic tree. Logic tree is a schematization tool used to visualize the dialogues' internal logics and underlying structures using a digraph method (Holcombe and Stein 1996; Wada et al. 2013). In its creation process, a top node represents a primary goal (greencolored node, top of Fig. 4.1) pursued in a vision of the scenario (e.g., a sustainable city). Under the primary goal, a series of secondary goals (red-colored nodes) (e.g., increased use of renewable energy, steady supply of resources and food, and extension of citizens' health expectancy) and means to achieve them (pink nodes) are put in a sequential manner so that a set of causal connections constituting the contents of the dialogues can be visually captured.

In accordance with the BC method, the WS participants were asked to set their goals first and then draw the means from such goals, not vice versa. In so doing, a 
chronologically backward way of thinking, a defining characteristic of $\mathrm{BC}$, was maintained. During the WS, we the facilitators recorded the entire dialogues and used audio recordings as sources while constructing logic trees. Simultaneously, we also turned to documented outputs of the dialogues. Logic trees made after the first of the WS sessions were presented to the participants and utilized at the second and third WS sessions to induce and organize participants' ideas and thoughts. After the final WS (the third), we produced the final versions of the logic trees. Thus, the two groups' dialogues resulted in two logic trees.

\subsubsection{Creating Multiple Scenarios}

With regard to the concept of urban sustainability transition, we presupposed (as mentioned in Sect. 4.1) that when the participants' interests, preferences, and knowledge are expressed in a more pluralistically divergent fashion, it is more likely that some will be mutually exclusive and contestable. From our perspectives, it is vital that the scenario-making process reflects these as such because they too contribute to important, indispensable aspects of the concept of sustainability that is complex, inclusive, and comprehensive in its nature and because plurality of citizens' interests and preferences on urban sustainability should not be completely diminished in light of democratic collective decision-making (Kishita et al. 2018).

In that regard, we employed at the WS a method (Mizuno et al. 2012, 2013) that enables drawing multiple, not one, visions as a result of one set of dialogues. Such a method basically utilizes "key factors" that are prioritized by the participants in the process of crafting their visions. In more concrete terms, we turned to the method in which the participants first pick ten most important "key words" with reference to the output of the logic tree resulting from their dialogue. During this process, it was suggested that they refer to the list (see Sect 4.2.2.2), and again were advised not to be constrained by it when making their top ten choices.

They then selected the top two of the ten key words by scoring both the degree of importance and the degree of mismatch between the current actual conditions and an ideal state in the future. These top two are then named as "key factors." With regard to each of the top two key factors, the participants were led to discuss and define two contrasting, contestable conditions and functions of their desirability for a future sustainable city. By crossing these two key factors just like two axes bisecting each other at right angles, this method enables generating four different visions (see Fig. 4.2). Thus, at the WS, the two groups generated eight visions in total (four each, see also Fig. 4.4 below).

\subsubsection{Choosing the Best Scenario}

During the final phase, each group deliberated on which one to choose as the best from those four visions. It was important that they did not have to turn to a majority decision if they did not want to. Rather, they were advised by the facilitators to 
Fig. 4.2 Crossing two key factors that have two contrasting features

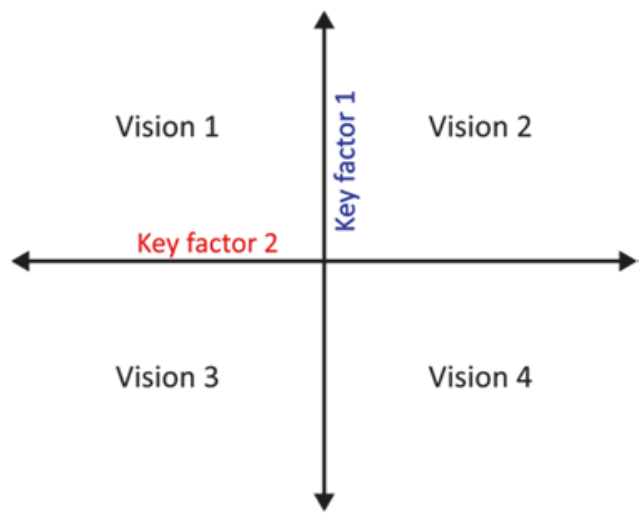

reach their consensus on how to decide their best vision to begin with. By employing this method, we sought to go beyond mere aggregation of established interests and preferences of the participants and to see if anything emerged to reshape and restructuralize a constellation of interests and preferences being manifested in the processes of their vision-making (Knight and Johnson 1994; Landemore 2013). The participants were to create a pathway only to the best vision, and a combination of such pathway and the best vision forms "the best scenario." This technique was used partly because of time constraints in the WS. As the final output, the WS resulted in the two best scenarios from the entire dialogues.

\subsection{Verification Approaches to Research Questions}

\subsubsection{Examination of Multiple Visions}

In verification processes, we first examined the processes and outcomes of the making of eight visions and the two best scenarios. In doing so, we basically look into an underlying question as to whether the contents of the visions could reflect and capture diverged interests, preferences, and knowledge of the participants despite the fact that the same methods and techniques (such as rules for dialogue, list of key items, logic tree, and scoring method) were evenly applied to the processes between Groups A and B. We in turn examine the processes by which the participants reached a consensus regarding the way to choose the best of their four visions, and in so doing, we also compare the outcomes of such visions between Groups A and B.

In taking these two approaches, we had presupposed that the more divergence reflected in the processes, the more the outcomes of the resulting four visions and best scenarios become independent of one another, meaning that they do not overlap in terms of their substance, by describing starkly different, or even mutually exclusive, states of the desirable future sustainable city. 

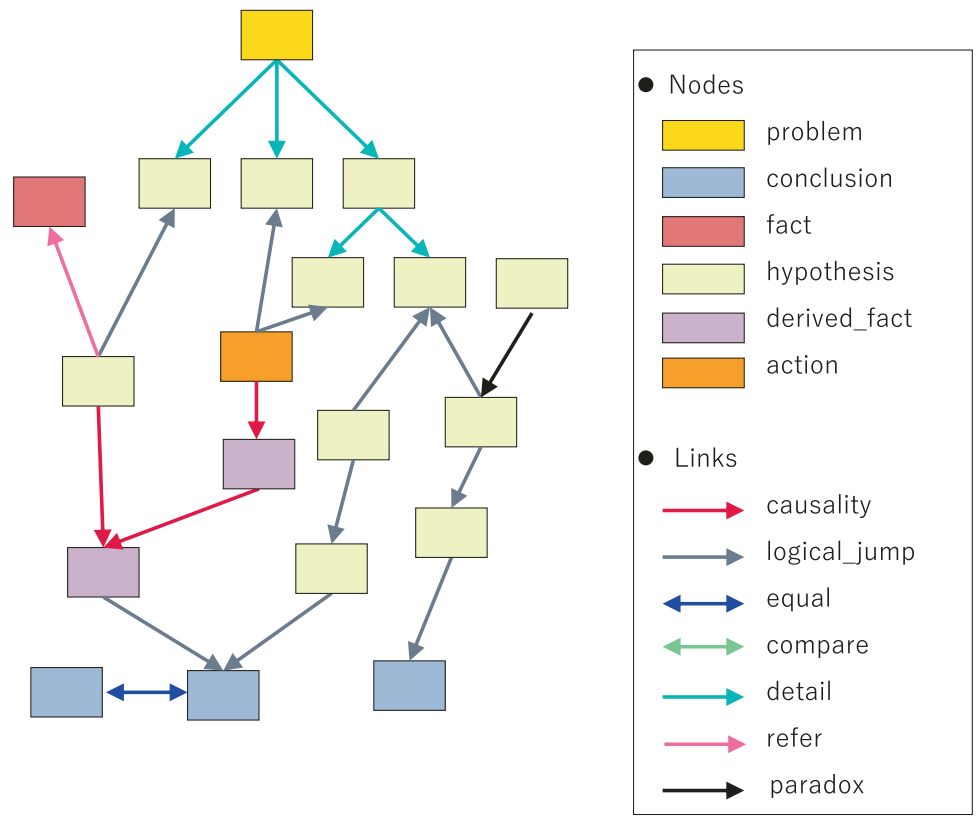

Fig. 4.3 Example digraph generated by $3 \mathrm{~S}$ simulator

\subsubsection{Use of the Sustainable Society Scenario (3S) Simulator}

The second approach is the use of a simulation technique called the "sustainable society scenario simulator" (hereafter $3 \mathrm{~S}$ simulator) proposed by one of the authors (Umeda et al. 2009; Kishita et al. 2009, 2010). The 3S simulator consists of an integrated supporting system developed for assisting us to comprehend, generate, and analyze scenarios concerning sustainable societies. The $3 \mathrm{~S}$ simulator utilizes a computational model and algorithms to describe, with visualization, cause-and-effect relationships, logic, and structures that are endogenous to particular scenarios.

For instance, as shown in Fig. 4.3 below, importing outputs drawn from the logic tree analyses and from the audio recordings made for the WS sessions, the $3 \mathrm{~S}$ simulator relies on the digraph method to visualize structures within the scenarios' contents by making linkages among a series of nodes. Each node and link are categorized in accordance with their attributes. Attributes of nodes that we used are: problem, conclusion, fact, hypothesis, derived fact, and action. Attributes of links are: causality, equal, logical jump, detail, refer, compare, and paradox (Umeda et al. 2009; Shelby et al. 2011). It can be understood that the order of these seven links basically indicates the degree to which each attribute consists of notions that are consistent with cause and effect and/or means-end relation. Thus, depending on how the attributes of nodes and links are aligned with one another, the degree of logical consistency attached to the contents of the scenarios can be evaluated. For instance, one can see that a scenario has a better logical consistency when its content can be 
described with a structure connected through a set of "causality" and "equal" links, rather than of "compare" and "paradox" links.

At the same time, however, it is important to understand that a "logical jump" link does not necessarily refer to a linkage that is logically inconsistent or false. It indicates a prospective inclusion of a breakthrough or innovative leap made within a boundary of limited "causality" that is yet to be of cause and effect and/or meansend relation. This loosened conceptualization of causality as a "logical jump" is required by the fundamental orientation of the $\mathrm{BC}$ method because the $\mathrm{BC}$ methodology is founded upon the rationale that a greater leap from the status quo and path dependency is needed to address the issues of sustainability transformation and its related structural changes (Kishita et al. 2009; Loorbach et al. 2016).

Furthermore, based on the above-mentioned methodology, we also turned to a numerical index system that quantifies the degree of such logical consistency. The index used is called the "logicality index" (hereafter LI) and is defined as the portion of arguments which are only constructed upon "causality" and "equal" links as compared to all other arguments. A formula used for our judgment hereby is that higher LI means better credibility of a scenario. In our concern for the efficacy and implementability of the $\mathrm{BC}$ scenarios as policy instruments, the degree of credibility can be an important indicator because it affects the extent to which $\mathrm{BC}$ scenarios can be accepted in society by embedding and incorporating them into the ongoing practical policy processes (Alcamo et al. 2008; Kishita et al. 2009).

In this study, therefore, we relied on LI to examine how credible the best scenarios generated by Groups A and B were. At the same time, we also turned to the $3 \mathrm{~S}$ simulator to gauge $\mathrm{LI}$ in the existing scenarios of future sustainability. Note that all of such scenarios were made only by relevant professionals and experts and include ones that were made by following not only the BC but also FC methods and a combination of both. From our analytic perspective, whether or not the LIs of these future sustainability scenarios scored better than those of the best scenarios made during the WS, can be an important verification indicator.

\subsection{Results, Analyses, and Discussion}

\subsubsection{Divergent Opinions Reflected in the Scenarios}

Table 4.2 shows the lists of ten key words chosen by each group. One can see that: (1) notwithstanding the fact that many key words were chosen from the list of the "key items" (see Sect. 4.2.2.2) given to each group by the facilitators, the participants' came up with their own choices, (2) choices for the ten "key words" differ a great deal between the two groups.

In addition, as shown in Fig. 4.4, each group made very different choices on the key factors as well. One can also find that the important aspects the WS participants placed their visions are not similar to one another in the sense that each of the four visions has its own characteristics, and that these do not overlap in terms of direction and content. 

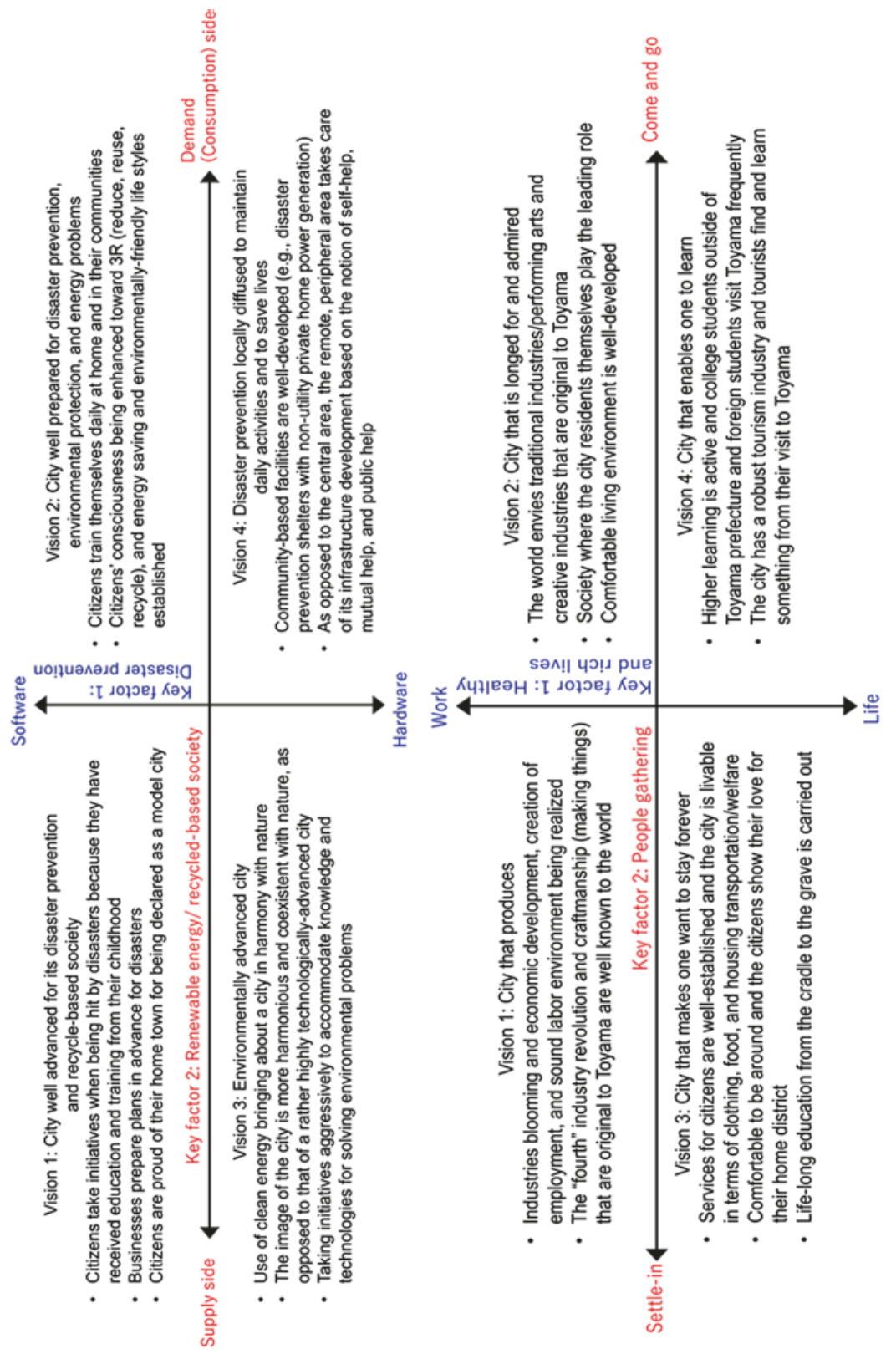

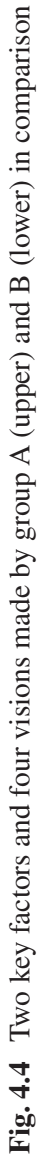


Table 4.2 Differences in ten key words chosen by each group

\begin{tabular}{l|l}
\hline Group A & Group B \\
\hline Civic prides & People gathering \\
\hline Disaster prevention & New culture \\
\hline Health/welfare & Transportation \\
\hline Renewable energy & Education \\
\hline One of a kind community & Happiness \\
\hline Internet of things & Good life/rich life/life of affluence \\
\hline Way of living/way of working & Health \\
\hline Tourism/migration (moving-in) & Vigorousness/bustling \\
\hline Labor population & Harmony \\
\hline Recycle-based society & Love for one's home town \\
\hline
\end{tabular}

Such diverged processes finally resulted in the two best scenarios whose visions' characteristics were significantly different from each other. The WS participants went on to discuss the paths that they thought necessary to realize such visions. Table 4.3 below shows the titles and some elements of the visions and paths. One can then be noted that the contents of these visions and paths reflected some important aspects of socioeconomic and socio-ecological concerns, which are elaborated as follows.

First, Group A's best scenario (Table 4.3, left column) indicated that considering the city's unique landscape characteristics (see Sect. 4.2.2.1), the WS participants proposed "dual residency" as a new type of lifestyle to achieve mutual harmony and benefit between the central and the peripheral areas. For this to be realized, they acknowledged that given the fact that prioritized allocation of TCG's budgets and resources would inevitably be held in the future, the citizens should turn off their ongoing tendency to depend on administrative services (i.e., government interventions and enterprises) and should instead have the mindset to cultivate and strengthen the spirit of self-help and/or mutual help compared to that of public help. They tended to regard such change in the division of roles between public and private spheres necessary to make their future city sustainable as a more unified entity.

Second, Group B's best scenario (Table 4.3, right column) contemplated that in order to earn people's admiration, the city would want capacity development in term of its production and education. That is because the WS participants thought that a place could attract people and have them stay there when residents felt enriched by and engaged in continuous, life-long learning that would also form the basis of sustainable production and provision of goods and services for its society. Thus, in the path toward 2064, implementation processes of creating Toyama's own industries and businesses ("city's original quaternary industry") were understood as vital. In such processes, the participants envisioned that the citizens should become as creative and unique as possible in their activities of daily living. They then acknowledged that such conduct could take place to a greater degree when the citizens fully learned and utilized the city's long-standing rich natural capitals (mountains, rivers, sea, paddies, and sceneries) and related cultural heritages (traditional arts and food cultures associated with water, rice, and fishes) that together constitute some important aspects of its socio-ecological landscape. 
Table 4.3 Titles and elements of best scenarios (visions and pathways) in comparison

\begin{tabular}{|c|c|c|}
\hline & Group A & Group B \\
\hline Titles & $\begin{array}{l}\text { Environmentally advanced city that is } \\
\text { also harmonious and coexists with nature }\end{array}$ & $\begin{array}{l}\text { A city that people around the world } \\
\text { admire }\end{array}$ \\
\hline $\begin{array}{l}\text { Elements } \\
\text { of visions }\end{array}$ & $\begin{array}{l}\text { - Harmonious with nature for expansion } \\
\text { of clean energy } \\
\text { - The concept of dual residency between } \\
\text { central and peripheral areas of the city } \\
\text { is well received } \\
\text { - As results of compact-city-related } \\
\text { policies, public services and various } \\
\text { facilities accumulate in the central } \\
\text { area } \\
\text { - In the peripheral area, residents solve } \\
\text { local matters via cooperation under the } \\
\text { spirit of self-help, mutual help, and } \\
\text { public help }\end{array}$ & $\begin{array}{l}\text { - To develop noble and distinctive } \\
\text { humanity via vigorous and thorough } \\
\text { life span inner education } \\
\text { - To vitalize industries original in } \\
\text { Toyama (traditional and/or } \\
\text { entertainment industries, creative } \\
\text { industries) } \\
\text { - To introduce to and be admired by the } \\
\text { world regarding citizens' distinctive } \\
\text { humanity and the city's original } \\
\text { quaternary industry } \\
\text { - To establish an academic city and } \\
\text { actively engage in conversational } \\
\text { exchanges of ones' opinions }\end{array}$ \\
\hline $\begin{array}{l}\text { Elements } \\
\text { of paths }\end{array}$ & $\begin{array}{l}\text { [from } 2016 \text { to } 2030 \text { ] } \\
\text { - To educate the citizens on disaster } \\
\text { prevention and environment } \\
\text { - To accumulate knowledges by inviting } \\
\text { experts and making study tours to } \\
\text { other cities } \\
\text { - To designate model sections within the } \\
\text { city } \\
\text { [from } 2030 \text { to 2064] } \\
\text { - To propose and accelerate the concept } \\
\text { of dual residency between the central } \\
\text { and peripheral areas } \\
\text { - To develop clean energy that utilizes } \\
\text { the resources of the Toyama } \\
\text { prefectures }\end{array}$ & $\begin{array}{l}\text { [from } 2016 \text { to 2030] } \\
\text { - To secure fiscal revenues } \\
\text { citizens (moral education, performing } \\
\text { arts, and discourses on religion and } \\
\text { history) } \\
\text { - To engage in public relations } \\
\text { internationally } \\
\text { [from } 2030 \text { to 2064] } \\
\text { - To develop the city's own (original) } \\
\text { industries via handing down of } \\
\text { traditional arts and crafts and via } \\
\text { innovating creative industries } \\
\text { - To develop the city's infrastructures } \\
\text { regarding scenery (landscape) and } \\
\text { public transportation }\end{array}$ \\
\hline
\end{tabular}

\subsubsection{Convergence Found from the BC Scenarios and Their Making}

\subsubsection{Merged into a Holistic, "Systemness" Perspective}

It is important to note that the WS participants did not end up identifying mutually exclusive, contrasting features in their choices of "key factors." Described in Sect. 4.2.2.4 above, we had expected in advance that their divergent opinions can be better reflected by two different, possibly contrasting dimensions attached to the key factors. However, it appears that they saw mutually complementary features that together apparently constitute essential aspects of the city's societal functioning represented by each of the four key factors. For instance, one key factor "disaster prevention" is an essential aspect of the sound functioning of a societal system where a city seeks to become more sustainable in the future. Coming 
up with "software" and "hardware" to define and characterize such functioning is not only rightly attuned to divergence concerns, but is also attuned to bolster and leverage that functioning through utilizing some sort of holistic viewpoint or, we might rather say, a "systemness" perspective. This can be the case because disaster prevention can never properly function as a societal system without either of the two features. Also, it is more than significant that one can find such a systemness perspective running throughout the other three key factors as well.

Furthermore, we argue that this systemness perspective may also be found in the way in which both groups came up with their best visions. Each group's participants did not just pick one out of the four visions as the best. Instead, what each group did was to merge these four into a single vision. Group A, for instance, named such vision as "environmentally-advanced city that is also harmonious and coexists with nature" because, while centering on vision 3 , its members also took elements and features (such as solving local matters via cooperation under the spirit of self-help, mutual help, and public help and being harmonious with nature for expansion of clean energy) from the three other visions. This took place simultaneously in both groups and occurred without their being instructed to do so by the facilitators and without their resorting to any types of majority decision.

As a consequence, we argue that their choosing the best vision apparently entailed a rather holistic, systemness perspective, by which the participants brought together aspects of societal functioning that they thought are needed for their version of the future desirable city to become more sustainable. If this is the case, we can point out that by finding a way to reach consensus on their own, the participants far exceeded our ex ante expectations in terms of going beyond the mere preference aggregation type of decision-making (see Sect. 4.2.2.5).

\subsubsection{Textual Structures Backed by Logical Consistency}

Based on the $3 \mathrm{~S}$ analyses, we found that the contents of both groups' best scenarios were aligned with the form of structure visually expressed by a set of means-end chains linked among the nodes (Fig. 4.5). As mentioned in Sect. 4.3.2 above, this in turn means that both scenarios equally entailed a degree of internally coherent, logical consistency in each of their structures. Considering the fact that the two scenarios significantly differed in their substance (as discussed in Sect. 4.4.1), we claim that it is a worthy finding having some bearing on procedural legitimacy that might prove the efficacy and implementability of the citizen participatory approach and its processes toward $\mathrm{BC}$ scenario-making.

In terms of this internal logical consistency, what we also found from our $3 \mathrm{~S}$ analyses was congruent with our claim. As shown in Table 4.4, when compared, the LI numbers for both best scenarios (19\% for Group A, 10\% for Group B) were as good as the ones scored for the $\mathrm{BC}$ scenarios being made by three groups consisting of experts only $(20 \%, 15 \%$, and $9 \%)$. This suggests that as far as the internal logical consistency attached to the scenarios' textual structure is concerned, the same degree of credibility and/or robustness can be acquired by either experts' or lay citizens' participation in $\mathrm{BC}$ decision-making. 


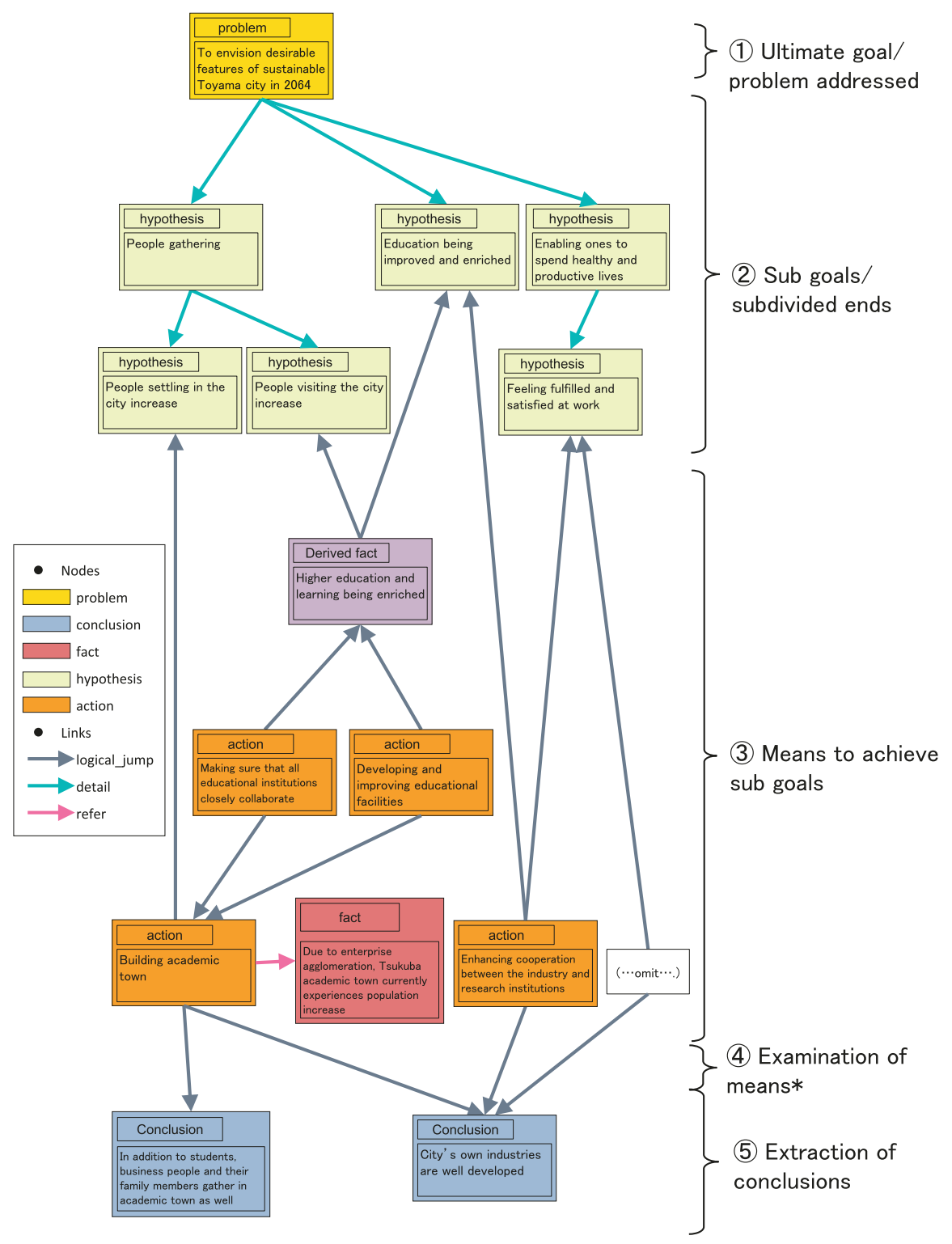

*Visuals of "(4) Examination of means" are omitted in this figure.

Fig. 4.5 Portion of the result of the 3S simulator analysis for Group B 
Table 4.4 LIs of various scenarios in comparison

\begin{tabular}{l|l|l}
\hline Scenarios & Methods & LI [\%] \\
\hline Group A's at Toyama WS & Backcast & 19 \\
\hline Group B's at Toyama WS & Backcast & 10 \\
\hline HEV diffusion scenario (Matsumoto et al. 2008) & Forecast & 58 \\
\hline IPCC GHG emission scenario (IPCC 2007) & Forecast & 47 \\
\hline ETP 2012 scenario (IEA 2012) & Forecast/Backcast & 20 \\
\hline $\begin{array}{l}\text { 2050 Japanese low carbon society scenario } \\
\text { Nishioka 2008) }\end{array}$ & Backcast & 15 \\
\hline $\begin{array}{l}\text { Sustainable manufacturing industry scenario } \\
\text { (Mizuno et al. 2014) }\end{array}$ & Backcast & 9
\end{tabular}

In addition, the very methods and procedures we employed in the WS can receive further credit because while the LIs for the lay citizens' BC scenario-making produced similar scores in comparison with the experts, the LIs also were much lower than the ones scored under the FC method $(58 \%, 47 \%)$. This in turn suggests that the intended functioning of the $\mathrm{BC}$ methods was secured as expected so that more logical jumps departing from the status quo and/or breaking through path dependency might be found in the BC rather than in the FC method.

\subsubsection{Issue-Oriented Concerns Being Shared}

Furthermore, our 3S analyses found another convergence, where both groups' best scenarios had the same set of the subgoals being incorporated into their means and ends structures (see Fig. 4.5, (2) subgoals/subdivided ends). Such subgoals are "civic pride/love for one's home town," "health/welfare," and "preventing declining population." The findings here indicate that the WS participants happened to share the same issue-oriented concerns, and those concerns are the ones that were actually considered and pursued through relevant policies and measures by the TCG. Also, this finding becomes more intriguing when we consider the fact that the ways in which the nodes were linked differed significantly between the two groups' scenario structures.

\subsection{Conclusions and Implications for Further Research}

Based on the analytical results shown above, we argue that while a broad spectrum of socioeconomic and ecological elements was incorporated, lay citizens' unrestrained dialogues in the WS sessions generated scenarios with a notably good degree of logically coherent, means-end-based structures and even projected what appeared to be a holistic, systemness-oriented perspective. In rhetorical terms, it can be said that once dispersed dots were connected to engender forms/texts backed by certain rational bases. Accordingly, we find it reasonable to conclude that when 
governed in certain ways, citizen participatory approaches can hit a fairly good balance between diverged processes and converged outcomes of BC scenario-making on the issue of urban sustainability transition. This leads us to claim that by way of ascertaining a required level of credibility, such a finding serves to prove and enhance practicality and implementability of BC scenarios that are considered daily policy instruments.

Among other possible contributing factors, the ones most significant to this favorable result would be the combination of logic trees and the list of key items. While it is plausible that these two aspects synergistically provided the WS participants with a good deal of reference focal points affecting the ways in which their dialogues were framed and constructed, each of the two groups ended up having their divergent opinions reflected in the scenarios' substances. Considering the fact that envisioning sustainability of future cities inevitably demands embracing pluralistic ideas and reflecting a set of multiple value systems (Umeda 2008; Kishita et al. 2010; Lang et al. 2012; Kanie 2017), we consider that the methods and processes we employed in the WS have some credibility toward achieving this goal.

Furthermore, our 3S analyses found that three issues - civic pride, health/welfare, and dealing with population decline-were equally recognized by both groups as important aspects to be pursued and realized when considering desirable features and functions of their future city. Even if those three issues were induced to be participants' significant interests because of the framing effects associated with the list of key items, we argue that this still conveys an important implication, particularly from a practical policy viewpoint. Notwithstanding the fact that the two groups came up with significantly different scenarios, it was shown that all the participants could reach a consensus on the importance and necessity of the same three policyrelated issues. We tend to interpret such a phenomenon as manifestation of "core beliefs" held by the participating citizens acting as a collective decision-making entity. The significance of such a finding in BC scenario-making should not be undervalued because it is central to the democratic procedural legitimacy attached to collective decision-making (Sandker et al. 2010; Lang et al. 2012).

Drawing from such an understanding, we assert that further analyses should be conducted to identify what types of relationships and dynamics exist within the dialogues and processes between the agreed three issues (i.e., core beliefs in our terms) and the converged textural structures. When explored in a positivistic/empirical manner, findings thereof will make a significant contribution to deeper understanding of the interaction and its mechanism between the two concepts of "divergence" (diverged processes and opinions) and "convergence" (converged outcomes and structures) inherently attached to BC scenario-making, especially viewed in the context of general citizens' consensus-building. At the same time, such studies will also contribute to advancing the understanding of the complex and multifaceted nature of a future city's function and its transition toward sustainability.

We therefore claim that the results of our study indicate that there exists the rationale for bringing about more and more lay citizens' direct participation in BC scenario-making in the future. Besides being often advocated in the relevant literature from a normative standpoint, the theme has not so far been addressed or 
examined in terms of empirical research, analyses, or backing data. In such sense, this chapter is a pioneering effort to fill these gaps.

Acknowledgements We would like to thank Program for Promoting Regional Revitalization by Universities as Centers of Community (COC+ Program) sponsored by MEXT and JSPS KAKENHI Grant Number JP16K00671 for their support in making Toyama workshops and this chapter possible, as well as the two anonymous reviewers for their insightful comments. We would also like to thank citizen participants in the workshops for their proactive participation.

\section{References}

Albert C (2008) Participatory scenario development for supporting transitions towards sustainability. In: Proceedings of 2008 Berlin conference on the human dimensions of global environmental change "long-term policies: governing social-ecological change," 2008

Alcamo J, Kok K, Busch G, Priessm JA, Eickhout B, Rounsevell M, Rothman DS, Heistermann M (2008) Searching for the future of land: scenarios from the local to global scale. In: Landuse and land-cover change: local processes and global impacts. Springer, Berlin, pp 137-155

AtKisson A, Lee Hatcher R (2001) The compass index of sustainability: prototype for a comprehensive sustainability information system. JEAPM 3(4):509-532

Bulkeley H, Betsill M (2003) Cities and climate change: urban sustainability and global environmental governance. Routledge, London

Carpenter S, Pingali P, Bennett E, Zurek M (2005) Ecosystems and human well-being: scenario: findings of the scenarios working group, millennium ecosystem assessment series, vol 2. Island Press, Washington, DC

Dreborg KH (1996) Essense of backcasting. Futures 28(9):813-828

Frantzeskaki N, Hölscher K, Bach M, Avelino F (eds) (2018) Co-creating sustainable urban futures: a primer on applying transition management in cities. Springer, New York. https://doi. org/10.1007/978-3-319-69273-9

Gallopin G, Hammond A, Raskin P, Swart R (1997) Branch point: global scenarios and human choice. PoleStar Series Report, no. 7. Stockholm Environment Institute, Stockholm. https:// greattransition.org/archives/other/Branch\%20Points.pdf

Glenn JC, The Future Groups International (2005) 13. Scenarios. In: Glenn JC, Gordon TJ (eds) Futures research methodology version 2.0. AC/UNU Millenium Project, Washington, DC

van der Heijden K (2005) Scenarios: the art of strategic conversation. Wiley, Chichester

Hodson M, Marvin S (2010) Can cities shape socio-technical transitions and how would we know if they were? Res Policy 39:477-485

Hodson M, Geels FW, McMeekin A (2017) Reconfiguring urban sustainability transitions, analysing multiplicity. Sustainability 9(2):299. https://doi.org/10.3390/su9020299

Holcombe MW, Stein J (1996) Presentations for decision maker, 3rd edn. Wiley, Chichester

International Energy Agency (IEA) (2012) Energy technology perspectives 2012. IEA Publications, Paris

International Panel on Climate Change (IPCC) (2007) Climate change 2007: synthesis report. Contribution of working groups III to the fourth assessment report of IPCC

Kanie N (2017) What is SDGs?: agenda for transformation towards 2030. Minervashobo, Kyoto. (in Japanese)

Kasemir B, Jäger J, Jaeger CC, Gardner MT (2003) Public participation in sustainability science: a handbook. Cambridge University Press, Cambridge

Kishita Y, Yamasaki Y, Mizuno Y, Fukushige S, Umeda Y (2009) Development of sustainable society scenario simulator-structural scenario description and logical structure analysis. In: Proceedings of the 16th CIRP international conference on life cycle engineering, 2009, pp 361-366 
Kishita Y, Mizuno Y, Fukushige S, Umeda Y (2010) Development of sustainable society scenario simulator - connecting scenarios with associated simulators. In: Proceedings of the 17th CIRP international conference on life cycle engineering 2010, pp 402-407

Kishita Y, Hara K, Uwasu M, Umeda Y (2016) Research needs and challenges faced in supporting scenario design in sustainability science: a literature review. Sustain Sci 11:331-347. https:// doi.org/10.1007/s11625-015-0340-6.

Kishita Y, McLellan BC, Giurco D, Aoki K, Yoshizawa G, Handoh IC (2017) Designing backcasting scenarios for resilient energy futures. Technol Forecast Soc Chang 124:114-125

Kishita Y, Masuda T, Nakamura H, Aoki K (2018) Exploring a participatory approach towards designing backcasting scenarios in the city of Toyama, Japan: prospective visions and pathways to the city's sustainable future. J Econ Stud 64(1):127-152. (in Japanese)

Knight J, Johnson J (1994) Aggregation and deliberation: on the possibility of democratic legitimacy. Political Theory 22(2):277-296

Kok K, van Vliet M, Barlund I, Dubel A, Sendzimir J (2011) Combining participative backcasting and exploratory scenario development: experiences from the SCENES project. Technol Forecast Soc Chang 78:835-851

Landemore H (2013) Democratic reason: politics, collective intelligence, and the rule of the many. Princeton University Press, Princeton

Lang DJ, Wiek A, Bergmann M, Stauffacher M, Martens P, Moll P, Swilling M, Thomas CJ (2012) Transdisciplinary research in sustainability science: practice, principles, and challenges. Sustain Sci 7(suppl 1):25-43

Loorbach D, Wittmayer JM, Shiroyama H, Fujino J, Mizuguchi S (eds) (2016) Governance of urban sustainability transitions: European and Asian experiences. Springer, Japan. https://doi. org/10.1007/978-4-431-55426-4

Mander SL, Bows A, Anderson KL, Shackley S, Agnolicci P, Ekins P (2008) The Tyndall Decarbonisation scenarios-part I: development of a backcasting methodology with stakeholder participation. Energy Policy 36:3754-3763

Matsumoto, M., Kondoh S, Fujimoto J, Masui K (2008) A modeling framework for the diffusion of green technologies. In: Management of technology innovation and value creation selected papers from the 16th international conference on management of technology, 2008, pp 121-136

Matsuoka Y, Harasawa H, Takahashi K (2001) Scenario approach on global environmental problems. J Jpn Soc Civil Eng II-19(678):1-11. (in Japanese)

McLellan BC, Kishita Y, Aoki K (2017) Participatory design as a tool for effective sustainable energy transitions. In: Sustainability through innovation in product life cycle design. Springer, Singapore. https://doi.org/10.1007/978-981-10-0471-1_40

Mizuno Y, Kishita Y, Wada H, Kobayashi K, Fukushige S, Umeda Y (2012) Proposal of design support method of sustainability scenarios in backcasting manner. In: Proceedings of the ASME 2012 international design engineering technical conferences \& computers and information in engineering conference: 17th design for manufacturing and the life cycle conference (DFMLC), DETC2012-70850

Mizuno Y, Kishita Y, Matsuhashi K, Miyake G, Murayama M, Umeda Y, Harasawa H (2013) An approach to designing sustainability scenarios part 1: a design method for backcasting scenarios. In: Proceedings of EcoDesign 2013, O-I-9

Mizuno Y, Kishita Y, Fukushige S, Umeda Y (2014) Envisioning sustainable manufacturing industries of Japan. Int J Autom Technol 8(5):634-643

Nishioka S (2008) Scenario for low carbon Society in Japan: a road to $70 \%$ reduction of $\mathrm{CO}_{2}$ emission. Nikkan Kogyo Shimbun, Ltd (in Japanese)

Robinson JB (1990) Futures under glass: a recipe for people who hate to predict. Futures 22(9):820-842

Rotmans J, van Asselt M, Anastasi C, Greeuw S, Mellors J, Peters S, Rothman D, Rijkens N (2000) Visions for a sustainable Europe. Futures 32:809-831

Sakano T (2011) Experimenting a method of deliberation-based social survey called deliberative poll. In: Inohara T (ed) Consensus building: theory, methods, and practice. Keisoshobo, Tokyo, pp 141-159. (in Japanese) 
Sandker M, Campbell BM, Ruiz-Perez M, Sayer JA, Cowling R, Kassa H, Knight AT (2010) The role of participatory modeling in landscape approaches to reconcile conservation and development. Ecol Soc 15(2):13

Shelby R, Perez Y, Agogino A (2011) Co-design methodology for the development of sustainable and renewable energy Systems for Underserved Communities: a case study with the Pinoleville Pomo nation. In: Proceedings of ASME 2011 international design engineering technical conferences and computers and information in engineering conference, 2011, pp 515-526

Soria-Lara JA, Banister D (2017) Participatory visioning in transport Backcasting studies: methodological lessons from Andalusia (Spain). J Transp Geogr 58:113-126

Ten Brink B, van der Esch S, Kram T, van Oorschot M, Alkemade JRM, Ahrens R, Bakkenes M, Bakkes JA, van den Berg M, Christensen V, Janse J, Jeuken M, Lucas P, Manders T, van Meijl H, Stehfest E, Tabeau A, van Vuuren D, Wilting H (2010) Rethinking global biodiversity strategies: exploring structural changes in production and consumption to reduce biodiversity loss. Netherlands Environmental Assessment Agency (PBL), Bilthoven

Toyama City (2017) Toyama City: people- and environment-friendly town (in Japanese). http:// www.city.toyama.toyama.jp/special/eco.html. Accessed 8 Jan 2018

Toyama City, Department of Planning and Coordination (2007) General plan of Toyama City: 2007-2016 (in Japanese). http://www.city.toyama.toyama.jp/data/open/cnt/3/8180/1/zentai. pdf. Accessed 8 Jan 2018

Tress B, Tress G (2003) Scenario visualisation for participatory landscape planning: a study from Denmark. Landsc Urban Plan 64:161-178

Umeda Y (2008) The need and approach of sustainable society scenario simulator. In: Ecodesign 2008 proceedings of the Japan symposium, A12-1 (in Japanese)

Umeda Y, Nishiyama T, Yamasaki Y, Kishita Y, Fukushige S (2009) Proposal of sustainable society scenario simulator. CIRP J Manuf Sci Technol 1(4):272-278

Vergragt PJ, Quist J (2011) Backcasting for sustainability: introduction to the special issue. Technol Forecast Soc Chang 78(5):747-755

Wada H, Kishita Y, Mizuno Y, Fukushige S, Umeda Y (2013) Proposal of a design support method of Backcasting scenarios for sustainable society. Trans Jpn Soc Mech Eng C 79(799):845-857. (in Japanese)

Wolfram M, Frantzeskaki N (2016) Cities and systemic change for sustainability: prevailing epistemologies and an emerging research agenda. Sustainability 8(2):144. https://doi.org/10.3390/ su8020144

Zellner M, Campbell SD (2015) Planning for deep-rooted problems: what can we learn from aligning complex systems and wicked problems? Plan Theory Pract 16:457-478

Open Access This chapter is licensed under the terms of the Creative Commons Attribution 4.0 International License (http://creativecommons.org/licenses/by/4.0/), which permits use, sharing, adaptation, distribution and reproduction in any medium or format, as long as you give appropriate credit to the original author(s) and the source, provide a link to the Creative Commons licence and indicate if changes were made.

The images or other third party material in this chapter are included in the chapter's Creative Commons licence, unless indicated otherwise in a credit line to the material. If material is not included in the chapter's Creative Commons licence and your intended use is not permitted by statutory regulation or exceeds the permitted use, you will need to obtain permission directly from the copyright holder.

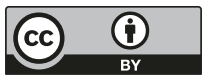

